\title{
Bridging Personality and Online Prosocial Behavior: The Roles of Empathy, Moral Identity, and Social Self-Efficacy
}

\author{
Jie Leng1, Qingke Guo ${ }^{2,1 *}$, Bingqing Ma ${ }^{1 *}$, Shuyue Zhang ${ }^{2 *}$ and Peng Sun ${ }^{3}$ \\ ${ }^{1}$ School of Psychology, Shandong Normal University, Jinan, China, ${ }^{2}$ Department of Psychology, Guangxi Normal University, \\ Guilin, China, ${ }^{3}$ Faculty of Psychology, Beijing Normal University, Beijing, China
}

OPEN ACCESS

Edited by:

Atsushi Oshio,

Waseda University, Japan

Reviewed by:

Elisabeth Malonda-Vidal,

University of Valencia, Spain

María Cristina Richaud,

Consejo Nacional de Investigaciones

Cientificas y Técnicas (CONICET),

Argentina

Yifeng Wang,

Sichuan Normal University, China

*Correspondence:

Qingke Guo

guoqingke@163.com

Bingqing Ma

472742004@qq.com

Shuyue Zhang

shuyuezh@126.com

Specialty section:

This article was submitted to Personality and Social Psychology, a section of the journal

Frontiers in Psychology

Received: 22 June 2020 Accepted: 26 August 2020 Published: 22 October 2020

Citation:

Leng J, Guo Q, Ma B, Zhang S and Sun $P$ (2020) Bridging Personality and Online Prosocial Behavior: The Roles of Empathy, Moral Identity,

and Social Self-Efficacy.

Front. Psychol. 11:575053. doi: 10.3389/fpsyg.2020.575053
Personality has been considered as important influential factors of prosocial behavior (PB). This study aims to investigate whether the personality-PB association revealed in the real world is applicable to cyberspace. Researchers further considered moral identity (MI), empathy, and social self-efficacy as mediators accounting for the association of personality and online prosocial behavior (OPB). Self-reported measures were administrated to 1398 participants from eastern China. Results showed (1) extraversion, agreeableness, conscientiousness, and openness were positively related to OPB, while neuroticism was negatively related to OPB; (2) perspective taking could serve as a mediator between all big five traits and OPB, social self-efficacy did the same job unless the predictor was agreeableness. Empathic concern and Ml were less important mediators partly because OPB involves no face-to-face interaction. These findings show that personality has a significant effect on OPB through its influence on moral development.

Keywords: personality, online prosocial behavior, empathy, moral identity, social self-efficacy

\section{INTRODUCTION}

The association of personality and prosocial behavior ( $\mathrm{PB}$ ) has been examined extensively. Literature shows that agreeableness and extraversion are positively associated with PB (Oda et al., 2014; Habashi et al., 2016), and neuroticism is negatively associated with PB (Habashi et al., 2016; Guo et al., 2018b). Over the past decades, popularization of the Internet facilitated the emergence of a new form of $\mathrm{PB}$, namely online prosocial behavior (OPB). OPB refers to behavior performed voluntarily to help others online without expectation of any reward. Typical OPB includes online donation, online sharing, and online comfort (Sproull, 2011; Erreygers et al., 2018; Zheng et al., 2018). OPB is similar to PB in benefiting others at the cost of the helper (Wright and Li, 2011; Reich, 2017; Guo et al., 2018a). However, the unique characteristics of OPB (e.g., less costly, anonymous, and less social pressured) are noteworthy (Lee and Lee, 2010; Zheng et al., 2018). Personality is an influential factor of online social behaviors (Amichai-Hamburger and Vinitzky, 2010). However, the personality-OPB association has not been well established. Therefore the first aim of this study is to investigate whether the personality- $\mathrm{PB}$ association persists in online settings.

If personality is linked to OPB, then what are the mechanisms accounting for this link? Literature suggests that moral cognition and moral emotions are dispositional factors motivating prosocial 
engagement (e.g., Eisenberg, 2000; Hardy, 2006). Moral identity (MI), the cognitive component of morality, is directly and strongly associated with PB (Blasi, 1980; Aquino and Reed, 2002). Empathy-related responding may be the most frequently studied moral emotions (Eisenberg, 2000). However, from a social cognitive perspective, empathy and MI may not facilitate prosocial engagement if the ability to alleviate others' distress is absent (Caprara et al., 2012). This suggests that interpersonal selfefficacy beliefs are also important determinants of PB. Based on above theorizing, the second aim of this study is to investigate whether the personality-OPB link can be accounted for by moral cognition (i.e., MI), moral emotion (i.e., empathy), and interpersonal self-efficacy beliefs (i.e., social self-efficacy).

\section{Personality and OPB}

Personality is relatively stable over time and can consistently predict a variety of social behavior (Specht et al., 2011; Hampson, 2012). The relationships between big five personality traits (Costa and McCrae, 1992) and PB have been extensively discussed. Evidence shows that personality is associated with $\mathrm{PB}$ assessed through self-report measures, suggesting that agreeableness, extraversion, openness, and conscientiousness are positively associated with $\mathrm{PB}$, while neuroticism is negatively associated with PB (e.g., Oda et al., 2014; Habashi et al., 2016; Xie et al., 2016; Guo et al., 2018b). These findings have been confirmed by researches using behavioral measures in both laboratory settings and in real world (e.g., Ben-Ner and Kramer, 2010; Courbalay et al., 2015; Habashi et al., 2016). However, a recent meta-analysis shows that extraversion and neuroticism are not related to $\mathrm{PB}$ measured in economic games (Thielmann et al., 2020). Thus the relationship between personality and PB need to be clearly addressed. To date only a few studies have explored the effects of personality on OPB. For example, openness was found to be positively associated with moral courage and help-giving both in real life and online (Kinnunen et al., 2016); and agreeableness and conscientiousness were positively associated with online information-sharing (Deng et al., 2017). These indicated that extroverted and open-minded (e.g., imaginative, curious) individuals tend to behave more positively online. However, shyness, a primary personality trait locating between introversion and neuroticism, was found to be negatively associated with OPB (Guo et al., 2018a). This citation suggests that introversion and neuroticism may also be negatively associated with OPB. But the effects of personality on OPB have not yet been soundly established, because previous studies have not used a comprehensive measure of OPB (Kinnunen et al., 2016; Deng et al., 2017), or have not directly investigated the roles of big five traits (Guo et al., 2018a).

Though online and offline behavior are similar in many aspects, such as both consume resources of the helpers, have no expectation of return of any benefit, occur in the organized social environment that requires positive social interactions (AmichaiHamburger, 2008; Wright and Li, 2011; Reich, 2017; Guo et al., 2018a), OPB has its unique features. For instance, helping online is less influenced by the help-seekers' physical appearance, the helpers can control the extent of involvement and the time schedule (Sproull, 2011). Moreover, OPB occurs anonymously, costs less resources, and generates less social pressures (Lee and Lee, 2010; Zheng et al., 2018). Therefore, whether the relationship between personality and OPB is similar to that in real life is still open to question. Literature shows that social competences developed in offline world are also applicable to online world (Subrahmanyam et al., 2006; Wright and Li, 2011; Reich, 2017). Online and offline worlds are psychologically connected (Wright and Li, 2011), thus the effects of social skills (or deficit) can be extended to the online world. Researchers also found that online behavior is positively related to daily social behavior offline, which indicates the consistence of offline and OPB (Ma et al., 2011; Wright and Li, 2011; Bosancianu et al., 2013). Besides, the cross-situational consistency of personality traits (Sherman et al., 2010; Specht et al., 2011; Hampson, 2012) suggests that personality may be associated with social behaviors in online and offline settings uniformly. Based on this theorizing, we propose that the effect of personality on PB can be extended to OPB.

\section{The Effects of Empathy, Moral Identity, and Social Self-Efficacy on PB/OPB}

Developmental psychologists have divided morality into three dimensions: moral cognition, moral emotion, and moral conduct (e.g., Kochanska et al., 2005; Jennings et al., 2015). MI refers to the extent to which being a moral person is central to that persons' self-concept (Aquino and Reed, 2002; Hardy and Carlo, 2011). As a social self-schema, MI can be represented by a set of traits organized around self-conception. It is a key psychological mechanism bridging moral reasoning and moral behavior (Aquino and Reed, 2002; Winterich et al., 2009). Aquino and Reed (2002) further distinguished two components (namely implicit and explicit) of MI. The former (MI internalization) reflects directly the degree to which moral traits are important to one's self-concept, while the latter (MI symbolization) reflects the degree to which an individual is inclined to convey publicly that s/he is a moral person (Aquino and Reed, 2002; Winterich et al., 2013). MI can positively predict charitable behavior (Hardy et al., 2015) and ethical behavior toward organizations (Hertz and Krettenauer, 2016). MI is more strongly predictive of PB than moral judgment, suggesting that MI can bridge the moral judge-action gap (Patrick et al., 2018).

Moral emotions (e.g., guilt, shame, empathy; Tangney et al., 2007) often exert stronger influences on moral actions than moral judgment (Jennings et al., 2015). Empathy refers to understanding and vicariously experiencing others' emotions (Eisenberg and Miller, 1987; Batson et al., 2015). Empathy plays a fundamental role in moral functioning (Eisenberg, 2000). According to Davis (1983), empathy contains two cognitive components, namely perspective taking (PT, spontaneously understanding other people's point of views) and fantasy (FS, imaginatively understanding the feelings of fictional characters in books or movies), and two emotional components, namely empathic concern (EC, an other-oriented feeling of sympathy or concern for the misfortune of others) and personal distress (PD, a self-oriented feeling of discomfort and uneasy when witnessing others in need). Higher scores on empathy indicate better abilities in understanding and experiencing other people's mental states, 
and greater sensitivity to their needs (Masten et al., 2011). Otheroriented empathic responses (e.g., EC) elicit behaviors aiming at reducing the distress of the victims, thus are more strongly associated with prosocial engagement. However, self-oriented responses (e.g., PD) are more likely to reduce uncomfortable feelings of the witness, leading to avoidance responses if able to do so (Eisenberger and Fabes, 1990; Carlo et al., 1999; Klimecki and Singer, 2011; Habashi et al., 2016). Empathy has also been shown to facilitate OPB. In cyberspace, empathic individuals show greater willingness to share, help, and donate (Khang and Jeong, 2016; Farrelly and Bennett, 2018).

Social self-efficacy may be associated with moral self-strength that can directly motivate moral actions (Jennings et al., 2015; Khang and Jeong, 2016). It refers to confidence in one's ability to participate in social interactions (Smith and Betz, 2000; Alessandri et al., 2009). People who lack social selfefficacy usually are unconfident in dealing with interpersonal interactions and solving problems for the victim, thereby showing less prosociality (Bandura, 1997; Habashi et al., 2016). Interpersonal self-efficacy influences the efficiency in managing social relationships and engaging in other people's emotional experiences, thereby exerting a direct impact on PB (Caprara and Steca, 2005). Caprara et al. (2010) found that trait interpersonal self-efficacy contributed to prosocial engagement. Recent literature suggests that the social self-efficacy and PB association is also applicable to online settings, showing that the belief in the ability to manage online social relationships positively predict OPB (Khang and Jeong, 2016).

\section{Personality and MI, Empathy, and Social Self-Efficacy}

A growing body of literature has examined the association between personality and moral behaviors, such as voluntary helping, cooperation, fairness, inclusiveness/prejudice, and universalism (for a review, see Smillie et al., 2019). This suggests that personality is predictive of moral cognition, emotion, and conduct.

Agreeableness and conscientiousness have been considered as quasi-moral traits that contribute to moral behaviors (Miller, 2007). For example, Krettenauer et al. (2014) found that agreeableness and conscientiousness can positively predict moral decision-making in hypothetical moral dilemmas and subsequent moral emotions. Agreeableness and conscientiousness have been considered as indicators of moral character that are inversely predictive of deviant behaviors (Kim and Cohen, 2015), such as academic dishonesty (Williams et al., 2010). These findings suggest that they can facilitate MI development. Openness is also associated with moral functioning. It is related to emotional sensitivity, social tolerance, political liberalism, and universalism (Miller, 2007). Ferguson et al. (2019) found that openness may facilitate costless prosociality that maximizing others' payoffs. Extraversion and neuroticism have seldom been studied as quasimoral traits (Miller, 2007), suggesting that MI cannot account for their associations with $\mathrm{PB}$.

All dimensions of the Big Five may be connected with empathy. Mooradian et al. (2011) found that agreeableness, extraversion, and conscientiousness were significantly correlated with PT and EC; neuroticism was correlated with PT (inversely) and PD, openness was correlated with all components of empathy. Highly agreeable people, featured by kindness and understanding, tend to have higher levels of PT and EC (Barrio et al., 2004; Melchers et al., 2016; Song and Shi, 2017). Neurotic individuals are susceptible to situational social stressor (Lee, 2009). They tend to be overwhelmed by negative emotions (PD) in front of the victims (Barrick and Mount, 1991; Roccas et al., 2002; Mooradian et al., 2011). Open-minded people are curious and imaginative (Barrick and Mount, 1991; Roccas et al., 2002), thus they have better PT and FS abilities. Conscientious people tend to manage social interactions (e.g., other people's emotions and desires) responsibly (Barrick and Mount, 1991; Miller, 2007; Hampson, 2012), therefore higher levels of empathy (e.g., PT, EC) are also expected in them. Extraversion is characterized by sociability and positive emotionality (Hampson, 2012). Greater responsiveness to others' emotions (e.g., PT, EC) is expected in extroverted individuals because positive emotions can broaden their scope of attention in social settings thereby triggering more positive responses (Fredrickson, 2004).

The association between personality and social self-efficacy has also been examined in previous literature. Mak and Tran (2001) found that extraversion (featured by sociability and positive emotionality), openness (featured by open-mindedness and tolerance for ambiguity), conscientiousness (featured by persistence, carefulness, and effortful control) are contributive to successful interpersonal communications, leading to higher levels of social self-efficacy in intercultural situations. Neuroticism (featured by social anxiety and avoidance in social situations), in contrast, was inversely associated with social self-efficacy (Mak and Tran, 2001).

\section{This Study}

The co-construction theory (Subrahmanyam et al., 2006) and the rich-get-richer/poor-get-poorer hypothesis (Kraut et al., 2002) both indicate that off-line and online world are connected. Based on these findings, we propose that people's social preferences in real world can extend to online world. For example, social skills deficit may hinder social interactions in both online and offline settings (Kraut et al., 2002; Wright and Li, 2011; Reich, 2017). And people who have a prosocial personality (Habashi et al., 2016) are more likely to help the needy regardless they emerge in real life or in cyberspace (Wright and Li, 2011; Guo et al., 2018a). Given above, we assume that agreeableness (Hypothesis 1a), extraversion (Hypothesis 1b), conscientiousness (Hypothesis 1c), and openness (Hypothesis $1 d$ ) were positively associated with $\mathrm{OPB}$, while neuroticism (Hypothesis 1e) was negatively associated with OPB.

The mechanisms through which personality gets outside the skin (Hampson, 2012) to exert influences on PB have scarcely been investigated. MI, empathy, and social self-efficacy play fundamental roles in motivating prosocial engagement (Eisenberg, 2000; Aquino and Reed, 2002; Jennings et al., 2015). The similarity of PB and OPB suggests that MI, empathy and social self-efficacy may mediate the personality-OPB association. Specifically, we assume that extraversion may be positively 
associated with $\mathrm{OPB}$ via empathy and social self-efficacy (Hypothesis 2a); agreeableness may be positively associated with OPB (Eisenberg, 2000; Miller, 2007; Kim and Cohen, 2015) via empathy and MI (Hypothesis 2b); conscientiousness may be positively associated with OPB (Eisenberg, 2000; Miller, 2007; Kim and Cohen, 2015) via empathy, MI and social self-efficacy (Hypothesis 2c), and openness may do the same job (Hypothesis $2 d$ ); neuroticism may be negatively associated with OPB via empathy and social self-efficacy (Hypothesis 2e).

In this study only the internalization aspect of MI was examined (cf. Aquino et al., 2009; Decelles et al., 2012) because it directly taps the essence of this construct. Existing literature suggests that the internalization aspect of MI is more strongly predictive of $\mathrm{PB}$ than the symbolization aspect (Winterich et al., 2013). Four dimensions of empathy were all examined in this study because they play different roles in influencing $\mathrm{PB}$ (Habashi et al., 2016).

\section{MATERIALS AND METHODS}

\section{Participants and Procedure}

A total of 1398 college students $\left(\mathrm{M}_{\text {age }}=19.04, \mathrm{SD}_{\text {age }}=1.22\right.$, $\left.N_{\text {male }}=566\right)$ from eastern China participated in this study in order to obtain course credits. $48.3 \%$ of their fathers and $60.2 \%$ of their mothers obtained a junior high school degree or lower, $28.0 \%$ of their fathers and $22.7 \%$ of their mothers obtained a senior high school degree, and $23.7 \%$ of their fathers and $17.1 \%$ of their mothers obtained a college degree. About $26.3 \%$ of them had a per capita monthly income of $¥ 500-1500,36.8 \%$ had $¥ 1500-3000$, and $36.8 \%$ had more than $¥ 3000$.

Informed consents were obtained from them. They completed a suite of questionnaire items measuring their demographic characteristics, big five personality, OPB, empathy, social selfefficacy, and MI (totally 107 items). Each time these measures were group-administrated to $30-50$ participants in university classrooms, with the supervision of two trained research assistants. Each participant received a pen as a gift (costing $¥ 3$ ) in compensation for participation and was informed of the purpose of the study. This study was in accordance with the ethical standards of the academic committee at Shandong Normal University and the 1964 Helsinki declaration and its later amendments. There were 63 participants whose responses had not been entered into the research database due to invalid answers (giving the same answer to all items of a questionnaire or failing to answer at least one of the questionnaire items).

\section{Measures}

\section{Personality}

The Big Five Inventory (BFI-44; Benet-Martinez and John, 1998) includes 44 items. Each item is rated using a five-point scale ranging from 1 (strongly disagree) to 5 (strongly agree). Example items are "Can be tense" (neuroticism; eight items), "Is talkative" (extraversion; eight items), "Has an active imagination" (openness; ten items), "Has a forgiving nature" (agreeableness; nine items), and "Does a thorough job" (conscientiousness; nine items). BFI has been validated in different cultural backgrounds
(Guo et al., 2018a; Oda et al., 2014). In this study, McDonald's omega (Dunn et al., 2014; Hayes and Coutts, 2020) of five sub-scales' were $0.74,0.77,0.72,0.71$, and 0.76 , respectively. Total score of each dimension was taken. Confirmatory factor analysis (CFA) showed that BFI-44 has good factorial validity $\left(\chi^{2} / \mathrm{df}=2.48 ; \mathrm{CFI}=0.94 ; \mathrm{TLI}=0.92 ; \mathrm{RMSEA}=0.03\right)$.

\section{Online Prosocial Behavior}

Online prosocial behavior was measured by a short version of the Internet Altruistic Behavior Scale (IABS) (Zheng et al., 2011). It contains fourteen four-point $(1=$ never, $4=$ always $)$ items, measuring three dimensions of OPB (i.e., online support, online mentoring, online sharing). Sample items are "Caring and encouraging others" (online support), "Guiding others how to use the Internet more efficiently"(online mentoring), and "Sharing with others experiences of successful learning" (online sharing). Total score of all items represents the levels of OPB. CFA of the 14-item IABS yielded satisfying goodness of fit statistics $\left(\chi^{2} / \mathrm{df}=10.96\right.$; CFI $=0.91$; TLI $=0.90$; MSEA $\left.=0.08\right)$. McDonald's omega was 0.90 .

\section{Empathy}

The Chinese version (Siu and Shek, 2005) of the Interpersonal Reactivity Index (IRI-C) (Davis, 1983) was used to assess levels of empathy. This measure consists of 22 items measuring four dimensions (i.e., PT, EC, FS, and PD) of empathy. Each item was rated using a five-point scale ranging from 0 (does not describe me well) to 4 (describes me well). Example items are "Describe self as soft hearted" (EC; six items), "Tend to loss control in emergences" (PD; five items), "Imagine how people feel before I criticize them" (PT; five items), "Felt like one of the character in play/movie" (FS; six items). CFA was conducted to assess construct validity of this scale, yielding acceptable goodness of fit indices $\left(\chi^{2} / \mathrm{df}=3.96\right.$; CFI $=0.93$; TLI $=0.90$; RMSEA $=0.05$ ). McDonald's omega for PT was 0.71, for EC was 0.59 , for FS was 0.64 , and for PD was 0.75 . Total score of each dimension was taken.

\section{Moral Identity}

Chinese version of MI measure (MIM-C) was developed by Wan and Yang (2008) based on Aquino and Reed (2002). Participants were asked to read nine traits (compassionate, caring, friendly, fair, helpful, honest, generous, hardworking, and kind) describing a person, then imagine a person who has these characteristics and visualize how this person think, feel, and behave. Then the internalization subscale (including nine five-point Likerttype items) was used to assess MI. A sample item is "Being a person who has these characteristics makes me feel good $(1=$ strongly disagree, 5 = strongly agree)." Total score of all items was taken. McDonald's omega was 0.95 . Satisfying construct validity was found by CFA $\left(\chi^{2} / \mathrm{df}=5.73\right.$; CFI $=0.99$; $\mathrm{TLI}=0.99 ;$ RMSEA $=0.06$ ).

\section{Social Self-Efficacy}

Chinese version (Fan et al., 2006) of the Scale of the Perceived Social Self-Efficacy (PSSE) (Smith and Betz, 2000) contains 18 five-point items ( $1=$ no confidence at all, $5=$ complete confidence), assessing perceived self-confidence in 
social interactions. An example item is "How confident are you in making friends?" CFA of the scale yielded satisfying goodness of fit statistics $\left(\chi^{2} / \mathrm{df}=7.25\right.$; CFI $=0.93$; TLI $=0.91$; $\left.\mathrm{RMSEA}=0.07\right)$. McDonald's omega was 0.91 . Total score of all items was taken to represent level of social self-efficacy.

\section{RESULTS}

Procedural and statistical remedies were both applied to control common method bias (Podsakoff and Organ, 1986). First, participants were informed that they should complete the items according to their real experiences, and the results were irrelevant to their school records and would be kept confidentially. Second, Harman's one-factor analysis was conducted to examine whether the first factor can account for a large amount of variance. Exploratory factor analysis of all questionnaire items yielded 20 factors (communality was 0.58) with eigenvalue over 1, with the first factor only explaining $14.96 \%$ of the total variance. This suggests that common method bias was not serious.

\section{Correlation Analysis}

Descriptive statistics and partial correlation coefficients (control variables were gender, monthly income, and father' and mother' educational level) were presented in Table 1. Results indicated that correlations among research variables mostly reached statistical significance. Five personality traits except neuroticism were positively related to OPB, PT, EC, social self-efficacy, and MI internalization. Neuroticism was positively associated with $\mathrm{PD}$, while other personality dimensions' were negatively associated with $\mathrm{PD}$. OPB was positively correlated with PT, EC, FS, social self-efficacy, and MI internalization.

\section{Multiple Mediation Analysis}

In order to identify multiple mediation mechanisms in the relationship between personality and $\mathrm{OPB}$, structural equation models (SEM) were constructed using Amos (Version 20;
Preacher and Hayes, 2008). Each time one personality trait was used as an independent variable and OPB was used as the outcome, with different mediators accounting for their association. Besides, demographic variables (i.e., gender, monthly income, father's and mother's educational level) was used as control variables in each model (see Model 1 to 5). All hypothesized models fitted the data well (Table 2). Multiple mediation analysis was conducted using PROCESS micro for SPSS (Hayes, 2012) with bias-corrected bootstrap method (5000 bootstrap samples, 95\% confidence interval). Results were presented in Table 3.

Empathy and social self-efficacy were hypothesized to be mediators in the extraversion-OPB association (Model 1). Mediation analysis showed that PT, EC, FS, PD, and social selfefficacy could be significantly predicted by extraversion, but only PT, EC, and social self-efficacy had significant positive effects on OPB (Figure 1). The mediating effect of PT, EC, and social selfefficacy were significantly positive, explaining 10,3 , and $52 \%$ of the total effect, respectively.

Empathy and MI internalization were assumed to mediate the agreeableness-OPB association (Model 2). Mediation analysis showed that PT, EC, FS, PD, and MI internalization could be significantly predicted by agreeableness, but only PT, MI internalization positively predicted OPB (Figure 2). Thus the mediating roles of PT and MI internalization were identified, explaining 20 and $19 \%$ of the total effect, respectively.

Empathy, MI internalization, and social self-efficacy were assumed to mediate the conscientiousness-OPB association

TABLE 2 | Model fit indexes.

\begin{tabular}{lcccc}
\hline Model & $\chi \mathbf{2} / \mathbf{d f}$ & CFI & TLI & RMSEA \\
\hline Model 1 (extraversion) & 4.505 & 0.960 & 0.925 & 0.050 \\
Model 2 (agreeableness) & 5.281 & 0.969 & 0.941 & 0.055 \\
Model 3 (conscientiousness) & 6.409 & 0.964 & 0.944 & 0.062 \\
Model 4 (openness) & 6.415 & 0.959 & 0.921 & 0.062 \\
Model 5 (neuroticism) & 3.137 & 0.979 & 0.955 & 0.039 \\
\hline
\end{tabular}

TABLE 1 | Partial correlation coefficients between variables $(N=1398)$.

\begin{tabular}{|c|c|c|c|c|c|c|c|c|c|c|c|c|c|}
\hline & $M(S D)$ & 1 & 2 & 3 & 4 & 5 & 6 & 7 & 8 & 9 & 10 & 11 & 12 \\
\hline 1 extraversion & $25.28(5.10)$ & 1 & & & & & & & & & & & \\
\hline 2 agreeableness & $33.31(4.75)$ & $0.33^{\star \star \star}$ & 1 & & & & & & & & & & \\
\hline 3 conscientiousness & $29.03(5.07)$ & $0.31^{\star \star \star}$ & $0.39^{\star \star \star}$ & 1 & & & & & & & & & \\
\hline 4 openness & $35.85(5.85)$ & $0.39^{\star \star \star}$ & $0.30^{\star \star \star}$ & $0.36^{\star \star \star}$ & 1 & & & & & & & & \\
\hline 5 neuroticism & $23.75(4.83)$ & $-0.49^{\star \star \star}$ & $-0.45^{\star \star \star}$ & $-0.39^{\star \star \star}$ & $-0.22^{\star \star \star}$ & 1 & & & & & & & \\
\hline $6 \mathrm{PT}$ & $13.42(3.19)$ & $0.17^{\star \star \star}$ & $0.25^{\star \star \star}$ & $0.25^{\star \star \star}$ & $0.35^{\star \star \star}$ & $-0.15^{\star \star \star}$ & 1 & & & & & & \\
\hline $7 \mathrm{FS}$ & $16.52(3.94)$ & $0.09^{\star \star}$ & $0.17^{\star \star \star}$ & $0.06^{\star}$ & $0.20^{\star \star \star}$ & $0.07^{\star}$ & $0.32^{\star \star \star}$ & 1 & & & & & \\
\hline $8 \mathrm{EC}$ & $16.00(3.51)$ & $0.11^{\star \star \star}$ & $0.36^{\star \star \star}$ & $0.18^{\star \star \star}$ & $0.14^{\star \star \star}$ & $-0.08^{\star \star}$ & $0.28^{\star \star \star}$ & $0.40^{\star \star \star}$ & 1 & & & & \\
\hline 9 PD & $10.72(3.78)$ & $-0.21^{\star \star \star}$ & $-0.16^{\star \star \star}$ & $-0.26^{\star \star \star}$ & $-0.11^{\star \star \star}$ & $0.47^{\star \star \star}$ & 0.05 & $0.14^{\star \star \star}$ & -0.02 & 1 & & & \\
\hline 10 social self-efficacy & $60.60(10.35)$ & $0.54^{\star \star \star}$ & $0.34^{\star \star \star}$ & $0.32^{\star \star \star}$ & $0.40^{\star \star \star}$ & $-0.40^{\star \star \star}$ & $0.29^{\star \star \star}$ & $0.15^{\star \star \star}$ & $0.18^{\star \star \star}$ & $-0.28^{\star \star \star}$ & 1 & & \\
\hline 11 moral identity internalization & $26.98(10.63)$ & $0.15^{\star \star \star}$ & $0.38^{\star \star \star}$ & $0.44^{\star \star \star}$ & $0.22^{\star \star \star}$ & $-0.06^{\star}$ & $0.28^{\star \star *}$ & $0.42^{\star \star \star}$ & $0.83^{\star \star \star}$ & $0.21^{\star \star \star}$ & $0.20^{\star \star \star}$ & 1 & \\
\hline $12 \mathrm{OPB}$ & $33.02(8.42)$ & $0.25^{\star \star \star}$ & $0.25^{\star \star \star}$ & $0.22^{\star \star \star}$ & $0.30^{\star \star \star}$ & $-0.20^{\star \star \star}$ & $0.27^{\star \star \star}$ & $0.14^{\star \star \star}$ & $0.17^{\star \star \star}$ & -0.04 & $0.34^{\star \star \star}$ & $0.19^{\star \star \star}$ & 1 \\
\hline
\end{tabular}

${ }^{*} p<0.05 ;{ }^{* *} p<0.01 ;{ }^{* *} p<0.001$. 
TABLE 3 | Standardized specific indirect effect of personality on online prosocial behavior.

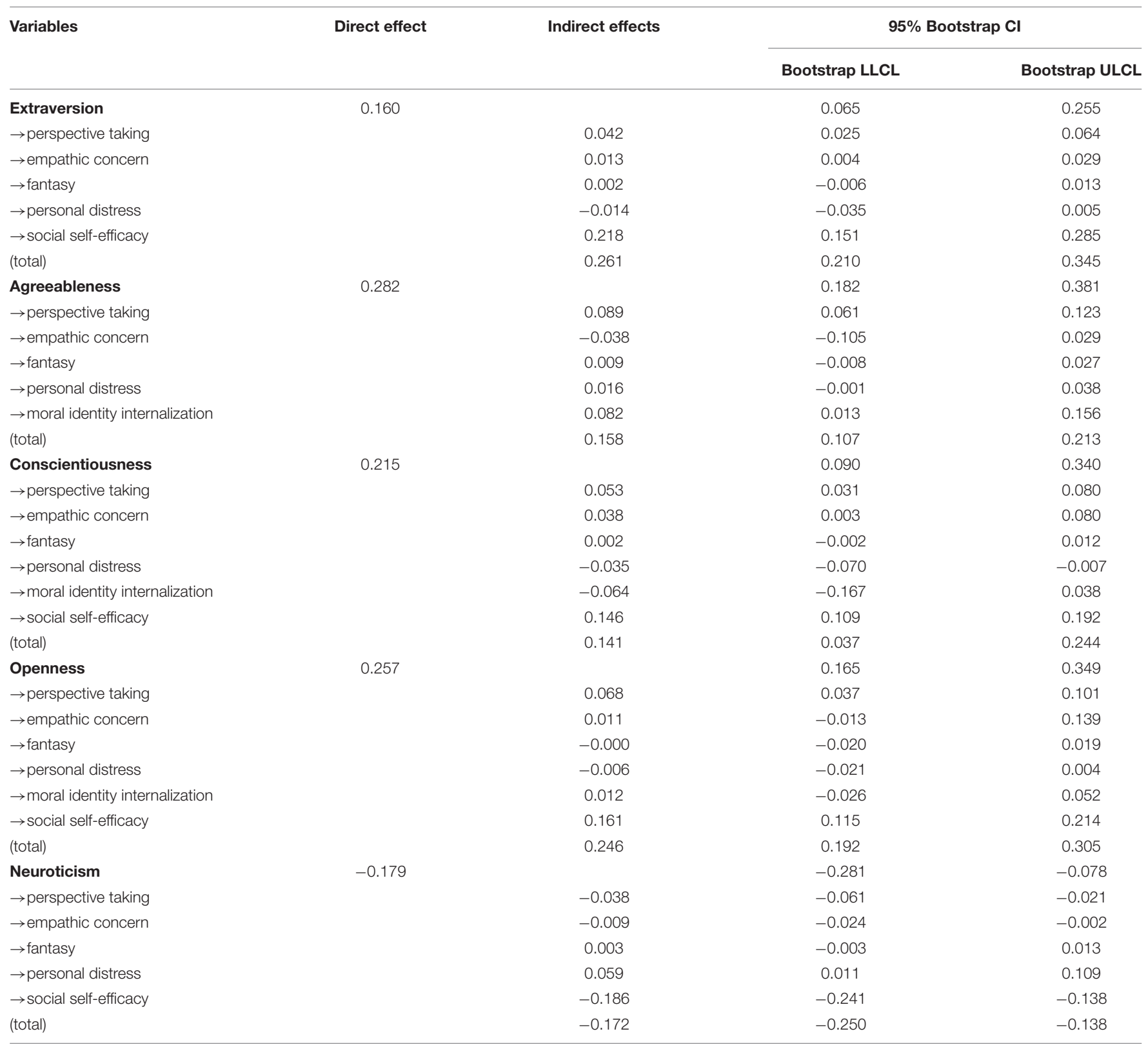

Note: Five personality dimensions' effects on online prosocial behavior through multiple mediation mechanisms were present in this table, respectively. The bold words stands for independent variables and the dependent variable of the five models is online prosocial behavior. (total) represents the total indirect effect. Gender, Monthly income, and father' and mother' educational level served as control variables.

(Model 3). Mediation analysis (Figure 3) showed that all hypothesized mediators could be significantly predicted by conscientiousness. However, only PT, EC, PD, and social self-efficacy had significantly positive effects on OPB. Thus the mediating roles of $\mathrm{PT}, \mathrm{EC}, \mathrm{PD}$, and social self-efficacy were identified, explaining $15,11,10$, and $41 \%$ of the total effect, respectively.

Empathy, MI internalization, and social self-efficacy were assumed to mediate the openness-OPB association (Model 4). Mediation analysis showed that openness had significant effects on PT, EC, FS, PD, MI internalization, and social self-efficacy.
Among them, PT and social self-efficacy had a significantly positive effect on OPB (Figure 4). Thus the mediating roles of PT and social self-efficacy were identified, explaining 13 and 32\% of the total effect, respectively.

Empathy and social self-efficacy were assumed to mediate the neuroticism-OPB association (Model 5). As shown in Figure 5, PT, EC, FS, PD, and social self-efficacy could be significantly predicted by neuroticism, in turn PT, EC, PD, and social selfefficacy positively predicted $\mathrm{OPB}$. Thus the mediating roles of $\mathrm{PT}$, EC, PD, and social self-efficacy were identified, explaining 11,3 , 17 , and $53 \%$ of the total effect, respectively. 


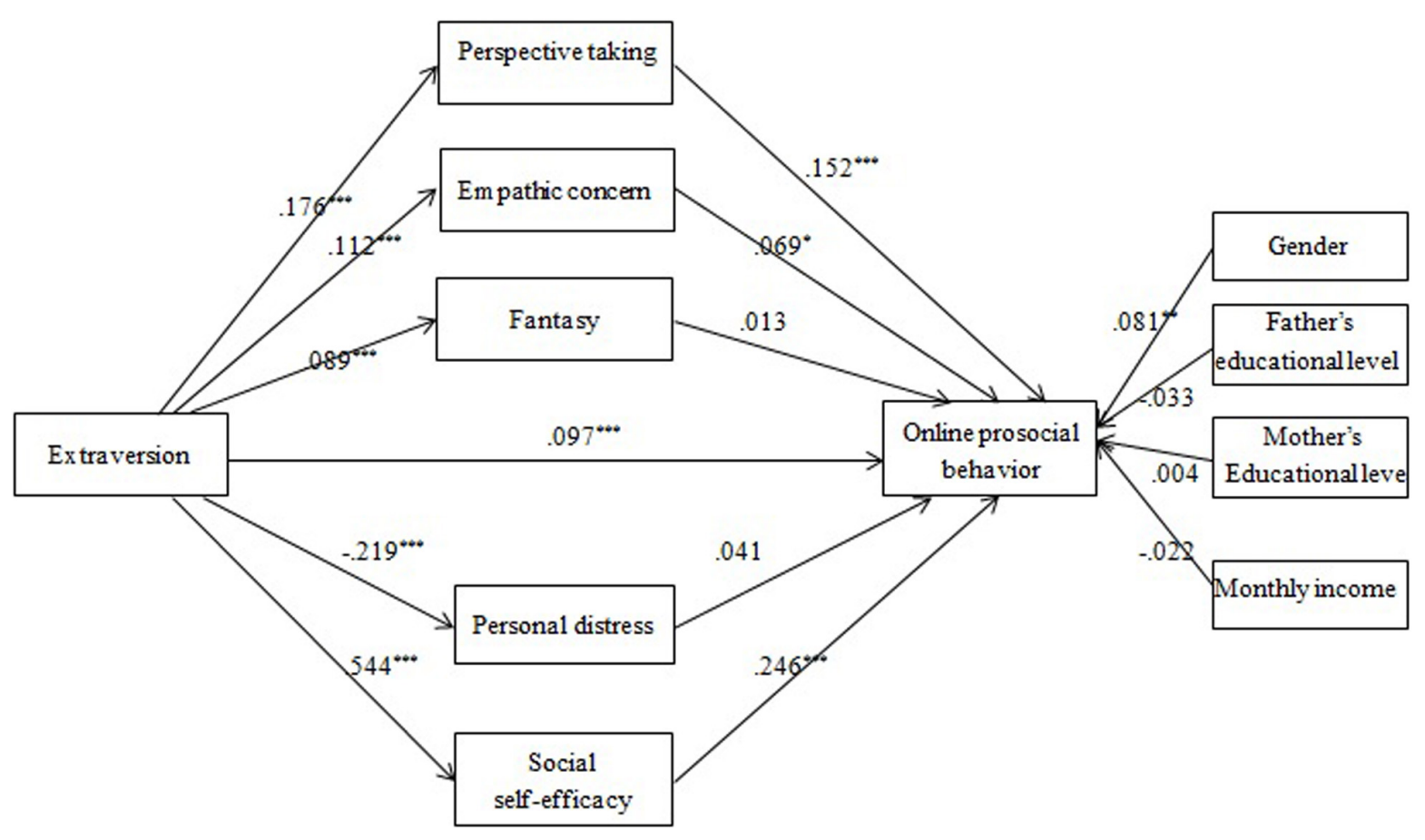

FIGURE 1 | The effects of multiple mediators in the extroversion-OPB association (Model 1): Coefficients standardized. ${ }^{*} p<0.05 ;{ }^{* *} p<0.01 ;{ }^{* \star *} p<0.001$.

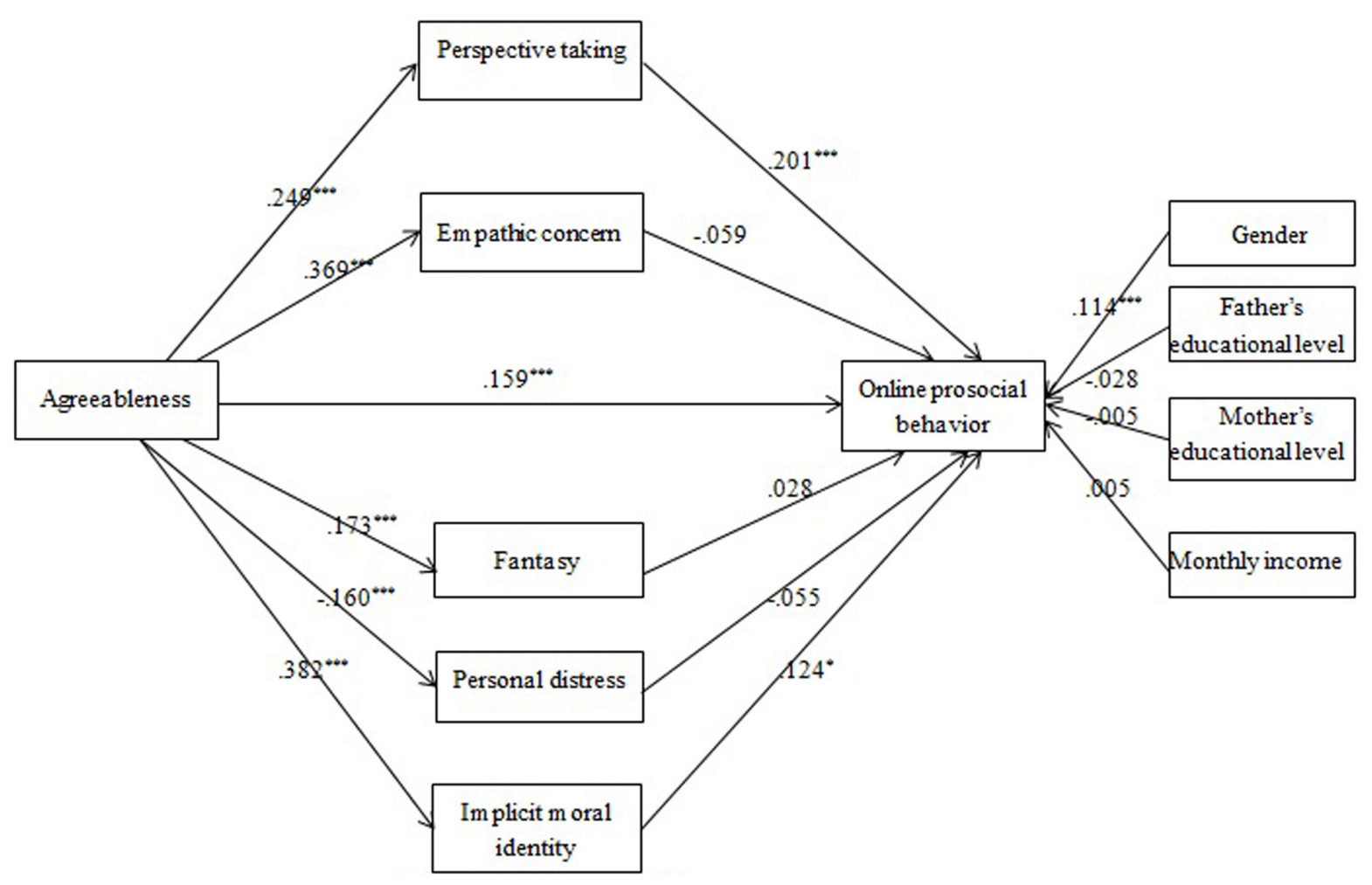

FIGURE 2 | The effects of multiple mediators in the agreeableness-OPB association (Model 2): Coefficients standardized. ${ }^{*} p<0.05 ;{ }^{* \star *} p<0.001$. 


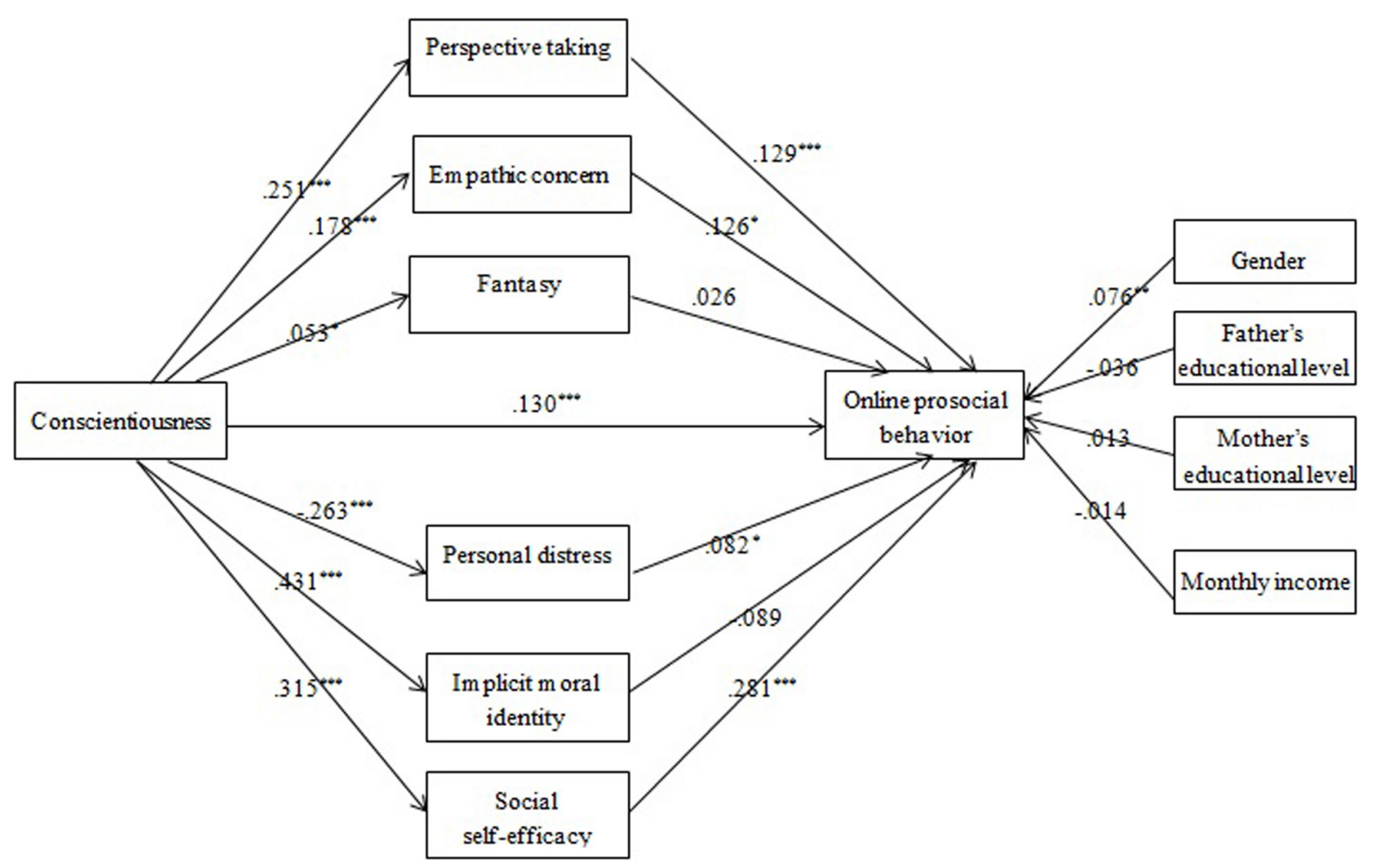

FIGURE 3 | The effects of multiple mediators in the conscientiousness-OPB association (Model 3): Coefficients standardized. ${ }^{*} p<0.05 ;{ }^{* *} p<0.01 ;{ }^{* * *} p<0.001$.

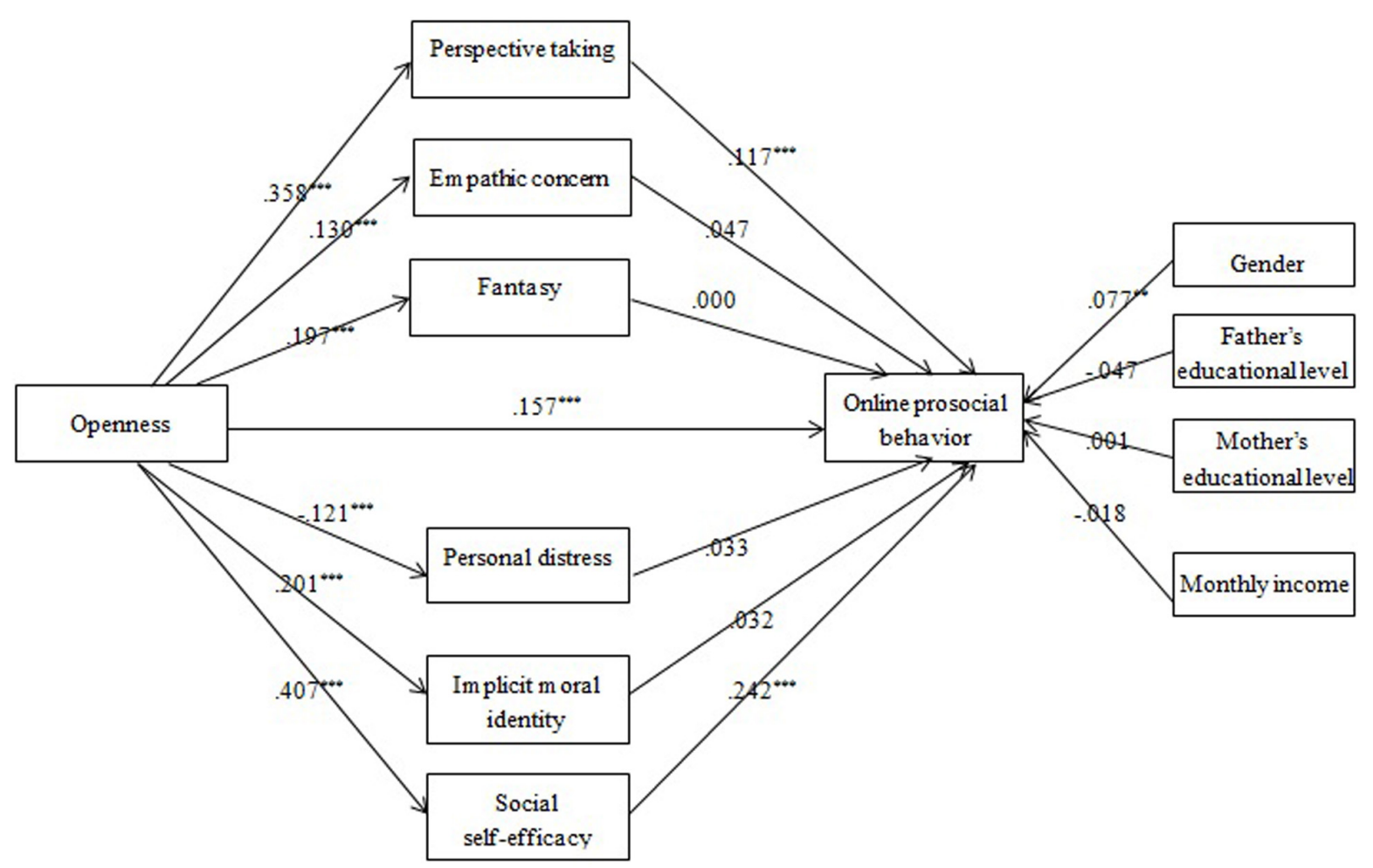

FIGURE 4 | The effects of multiple mediators in the openness-OPB association (Model 4): Coefficients standardized. ${ }^{* *} p<0.01 ;{ }^{* * *} p<0.001$. 


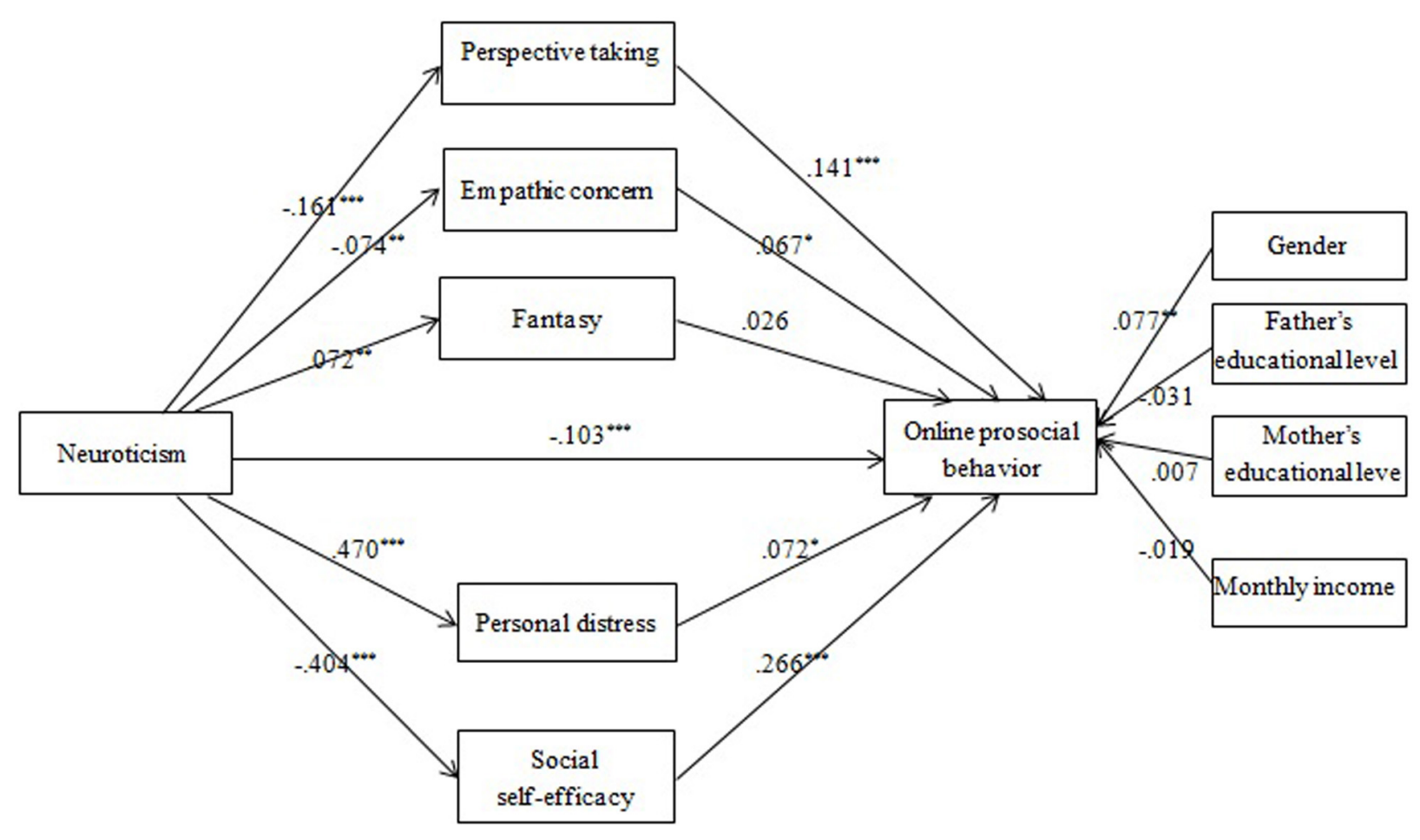

FIGURE 5 | The effects of multiple mediators in the neuroticism-OPB association (Model 5): Coefficients standardized. ${ }^{*} p<0.05 ;{ }^{* *} p<0.01 ;{ }^{* * *} p<0.001$.

\section{DISCUSSION}

Consistent with Hypothesis $1 a-e$, we found that the effects of extraversion, agreeableness, conscientiousness, and openness on OPB were all positively significant, while the effect of neuroticism was negatively significant. Our findings support the co-construction theory (Subrahmanyam et al., 2006) and the rich-get-richer/poor-get-poorer hypothesis (Kraut et al., 2002). That is, the effects of personality on social behaviors also apply to cyberspace (Oda et al., 2014; Habashi et al., 2016; Guo et al., 2018a). Though there are many differences between PB and OPB (Sproull, 2011), their associations with personality are consistent. For example, a negative neuroticism-OPB association suggested that the negative effects of low self-efficacy and lack of social skills on positive online social behavior cannot be reduced by convenience and anonymity of the Internet.

\section{Potential Mediators in the Personality-OPB Link}

From the multiple mediation models, we can learn that the relationships between five personality traits and OPB are all partly explained by several assumed moral-related mediators, especially PT and social self-efficacy.

In consistent with Hypothesis $2 a$, we found that extraversion could influence OPB through PT, EC, and social self-efficacy. A fundamental feature of extraversion is positive emotionality (Hampson, 2012). According to Fredrickson (2004), positive emotions can expand the scope of cognition and build enduring social resources, leading to greater engagement with the environments. Extended cognitive and emotional resources may lead an extrovert individual to be capable of caring for others' feelings (EC) and thinking from others' perspectives (PT) (Rosen and Kluemper, 2008). Melchers et al. (2016) also found that extraversion was positively related to PT and EC. Further, PT and EC facilitate approaching responses to others' sufferings, which in turn increase PB/OPB (Guo et al., 2018a). Moreover, extraverted individuals are sociable and talkative (Barrick and Mount, 1991), they have high self-efficacy in dealing with interpersonal relationships and engage in social interactions (Di Giunta et al., 2010). This belief contributes not only to positive social behaviors in real life (Caprara and Steca, 2005; Falanga et al., 2014), but also to social engagement in cyberspace (Khang and Jeong, 2016).

In consistent with Hypothesis $2 b$, we found that agreeableness could increase $\mathrm{OPB}$ via higher levels of PT and MI internalization. Agreeableness contains some traditional virtues such as kindness, cooperation, and soft-heartedness (Barrick and Mount, 1991), and has been viewed as a quasimoral traits (Miller, 2007). It is reasonable that agreeable people can develop a higher level of MI which in turn increases their engagement in moral behavior like $\mathrm{PB} / \mathrm{OPB}$ (Winterich et al., 2013). Furthermore, agreeable individuals are better in adopting other's views and understanding other people's needs (Song and Shi, 2017), and these PT skills are better predictors of OPB. Additionally, we found that unlike findings in real life situations, EC did not mediated the agreeableness-OPB association. Einolf (2008) proposed that the relationship between EC and helping are weak when help-seekers are not at the scene. OPB does not 
involve face-to-face interactions between the help-seekers and helpers (Sproull, 2011), thus the perception of the help-seekers' emotional states may be inaccurate (Barrett et al., 2011). Konrath et al. (2011) also suggested that no face-to-face interactions in cyberspace affect the perception and response to the suffering of help-seekers.

Partly in consistent with Hypothesis 2c, the effect of conscientiousness on OPB was mediated by PT, EC, PD, and social self-efficacy. Conscientious individuals are selfdisciplined and responsible in interpersonal situations. They are careful of other people's viewpoints and feelings (PT), and are ready to take actions to maintain interpersonal harmony and reduce inconsistencies (Song and Shi, 2017). These features are conductive to $\mathrm{PB} / \mathrm{OPB}$. The positive relationship between $\mathrm{EC}$ and conscientious, and negative relationship between $\mathrm{PD}$ and conscientious were also found by previous researches (Melchers et al., 2016). Though EC and PD also served as mediators in personality-OPB association, indirect effects of them were relatively weaker than that of PT. Conscientiousness is associated with self-discipline, effort-control, and industry, which are conductive to self-efficacy in social situations (Thoms et al., 1998; Mak and Tran, 2001; Karwowski et al., 2013). These findings suggest that PT and self-efficacy play important roles in linking conscientiousness and OPB. Inconsistent with Hypothesis $2 c$, the mediating effect of MI internalization was not significant. Though conscientiousness is a quasi-moral trait featured by impulse control and restraint (Miller, 2007; Hampson, 2012), its association with MI has not been soundly addressed. Other mediators (e.g., PT, self-efficacy) played stronger roles in the conscientiousness-OPB link than MI internalization.

In consistent with Hypothesis $2 d$, we found that openness can increase OPB via higher levels of PT and social selfefficacy. Openness is an indicator of cognitive ability, which is associated with involvement in community and PB (Aranda and Siyaranamual, 2014; Guo et al., 2019). Song and Shi (2017) found that there was a positive openness-PT association. Openness means sensitivity and insightfulness in understanding others and satisfying their needs (Costa et al., 2013), suggesting that open-minded individuals are better in thinking from the perspectives of others and act accordingly. Furthermore, openness means flexibility and tolerance for ambiguity in interpersonal communications, which are conductive to high social self-efficacy and greater willingness to help others online (Mak and Tran, 2001; Khang and Jeong, 2016). Surprisingly, FS, an empathy component most closely related to openness (Melchers et al., 2016), did not mediate the openness-OPB link. Results showed that the role of FS on OPB were not significant in this study and some researchers even found a negative relationship between FS and prosocial reasoning (Lai et al., 2012). These findings suggested that the effect of FS on prosocial engagement is quite limited. Additionally, MI internalization did not mediate the openness-OPB link. The reason may be that openness is not a core element of moral trait (Miller, 2007).

Consistent with our Hypothesis $2 e$, neuroticism was negatively related to OPB via lower levels of PT, EC, and social self-efficacy. Neurotic individuals are susceptible to negative emotions like anxiety and depression (Lee, 2009), which prevent them from putting themselves in other's places and caring for others feelings (Mooradian et al., 2011). Neuroticism is characterized by helplessness, poor self-control, and social avoidance, which will lead to lower social self-efficacy (Mak and Tran, 2001; Karimzade and Besharat, 2011), and consequently less prosocial engagement both online and offline. Consistent with Guo et al. (2018b), this study found that neuroticism could increase OPB through elevated PD. Witnessing others' sufferings are especially painful for neurotic individuals (Mooradian et al., 2011). And lend a helping hand to relieve others' sufferings is one way to alleviate PD of one own (Song and Shi, 2017). This can be the reason why neuroticism could facilitate $\mathrm{PB} / \mathrm{OPB}$ via elevated $\mathrm{PD}$.

This is the first study examining the mechanisms through which personality is associated with OPB. We found that personality traits influence OPB in different ways. First, the most important mediator is social self-efficacy, which directly translates personality into actual behavior (Jennings et al., 2015; Khang and Jeong, 2016). Previous literature suggests that morality is not conductive to prosocial engagement if the ability to meet the needs of the sufferers is absent (Sun et al., 2019). Second, another important mediator is PT. Understanding others' inner states may be the basis of other-oriented responses (Galinsky et al., 2008; Decety and Yoder, 2016). The role of EC is less important because OPB does not require face-toface interactions which may interfere with emotional perception (Einolf, 2008; Barrett et al., 2011; Konrath et al., 2011). Third, the mediating role of MI is less important than expected. Its mediating effect may have been suppressed by other mediators in the hypothesized models (Daniel et al., 2015; Taguri et al., 2018). Finally, based on the co-construction theory we further propose that the mediating mechanisms between the personality-OPB associations are similar to that in the personality-PB association.

\section{Limitations and Future Directions}

One limitation of this study is that the identification of mediators is not inclusive, leading to the fact that the personality-OPB association was only partially accounted for by these mediators. Other mediators, such as moral judgment (Eisenberg, 2000; Hardy, 2006), interpersonal trust (Deng et al., 2017), empathic self-efficacy (Caprara et al., 2010), should be examined in future studies. The second limitation is that the recipients of OPB have not been distinguished. OPB toward diverse types of recipient (e.g., friends, strangers) may be differently affected by personality (Oda et al., 2014). The third limitation is that the frequency of Internet use (Ryan and Xenos, 2011), which may be an important factor influencing online helping, has not been examined in this study. Additionally, using a OPB measure that has been only validated in Chinese context may limit the generalizability of the findings of this study.

Despite the above limitations, this study provides empirical evidence that personality can consistently affect PBs across different contexts. Besides, personality is stable and difficult to be changed, researchers and caseworkers can consider cultivating individuals' empathy (especially perspective taking) and social self-efficacy (the belief that one can perform well in social interactions) to effectively promote online $\mathrm{PB}$, so as to enable the helpers and recipients benefit more from the use of the Internet. 


\section{DATA AVAILABILITY STATEMENT}

The datasets presented in this study can be found in online repositories. The names of the repository/repositories and accession number(s) can be found below: https://osf.io/p32ye/ files/.

\section{ETHICS STATEMENT}

The studies involving human participants were reviewed and approved by the Academic Committee at Shandong Normal University. Written informed consent to participate in this

\section{REFERENCES}

Alessandri, G., Caprara, G. V., Eisenberg, N., and Steca, P. (2009). Reciprocal Relations Among Self-Efficacy Beliefs and Prosociality Across Time. J. Personal. 77, 1229-1259. doi: 10.1111/j.1467-6494.2009.00580.x

Amichai-Hamburger, Y. (2008). Potential and promise of online volunteering. Comput. Hum. Behav. 24, 544-562. doi: 10.1016/j.chb.2007.02.004

Amichai-Hamburger, Y., and Vinitzky, G. (2010). Social network use and personality. Comput. Hum. Behav. 26, 1289-1295. doi: 10.1016/j.chb.2010.03. 018

Aquino, K., Freeman, D., Reed, A., Felps, W., and Lim, V. K. G. (2009). Testing a social-cognitive model of moral behavior: the interactive influence of situations and moral identity centrality. J. Personal. Soc. Psychol. 97, 123-141.

Aquino, K., and Reed, A. (2002). The Self-Importance of Moral Identity. J. Personal. Soc. Psychol. 83, 1423-1440. doi: 10.1037/0022-3514.83.6.1423

Aranda, L., and Siyaranamual, M. D. (2014). Are smarter people better Samaritans? effect of cognitive abilities on pro-social behaviors. Soc. Sci. Electr. Publish. 60, 640-645. doi: 10.2139/ssrn.2435818

Bandura, A. (1997). Self-Efficacy: The Exercise Of Control. New York: Freeman.

Barrett, L. F., Mesquita, B., and Gendron, M. (2011). Context in emotion perception. Curr. Direct. Psychol. Sci. 20, 286-290. doi: 10.1177/ 0963721411422522

Barrick, M. R., and Mount, M. K. (1991). The big five personality dimensions and job performance: a meta-analysis. Person. Psychol. 44, 1-26. doi: 10.1111/j. 1744-6570.1991.tb00688.x

Barrio, V. D., Aluja, A., and García, L. F. (2004). Relationship between empathy and big five personality traits in a sample of Spanish adolescents. Soc. Behav. Personal. 32, 677-682. doi: 10.2224/sbp.2004.32.7.677

Batson, C. D., Lishner, D. A., and Stocks, E. (2015). The Empathy-Altruism Hypothesis. Oxford: Oxford University Press, 1-27.

Benet-Martinez, V., and John, O. P. (1998). Los Cinco Grandes across cultures and ethnic groups: Multitrait-multimethod analyses of the Big Five in Spanish and English. J. Personal. Soc. Psychol. 75, 729-750. doi: 10.1037/0022-3514.75.3.729

Ben-Ner, A., and Kramer, A. (2010). Personality and altruism in the dictator game: Relationship to giving to kin, collaborators, competitors, and neutrals. Personal. Indiv. Diff. 51, 216-221. doi: 10.1016/j.paid.2010.04.024

Blasi, A. (1980). Bridging moral cognition and moral action: A critical review of the literature. Psychol. Bull. 88, 1-45. doi: 10.1037/0033-2909.88.1.1

Bosancianu, C. M., Powell, S., and Bratović, E. (2013). Social Capital and Pro-Social Behavior Online and Offline. Int. J. Internet Sci. 8, 49-68.

Caprara, G. V., Alessandri, G., Di Giunta, L., Panerai, L., and Eisenberg, N. (2010). The contribution of agreeableness and self-efficacy beliefs to prosociality. Eur. J. Personal. Publ. 24, 36-55. doi: 10.1002/per.739

Caprara, G. V., Alessandri, G., and Eisenberg, N. (2012). Prosociality: The contribution of traits, values, and self-efficacy beliefs. J. Personal. Soc. Psychol. 102, 1289-1303. doi: 10.1037/a0025626

Caprara, G. V., and Steca, P. (2005). Self-Efficacy Beliefs As Determinants of Prosocial Behavior Conducive to Life Satisfaction Across Ages. J. Soc. Clin. Psychol. 24, 191-217. doi: 10.1521/jscp.24.2.191.62271 study was provided by the participants' legal guardian/ next of kin.

\section{AUTHOR CONTRIBUTIONS}

JL analyzed the data, wrote the original manuscript, and revised the manuscript. QG designed the work, provided data analysis ideas, and revised manuscript. BM helped revise the manuscript and performed the final proofreading. SZ helped revise the manuscript and provided statistical support for data analyzing. PS collected the data and provided data analysis software. All authors contributed to the article and approved the submitted version.

Carlo, G., Allen, J. B., and Buhman, D. C. (1999). Facilitating and Disinhibiting Prosocial Behaviors: The Nonlinear Interaction of Trait Perspective Taking and Trait Personal Distress on Volunteering. Basic Appl. Soc. Psychol. 21, 189-197. doi: 10.1207/S15324834BASP2103_3

Costa, P., Magalhães, E., and Costa, M. J. (2013). A latent growth model suggests that empathy of medical students does not decline over time. Adv. Health Sci. Educat. 18, 509-522. doi: 10.1007/s10459-012-9390-z

Costa, P. T., and McCrae, R. R. (1992). Revised NEO Personality Inventory (NEO $P I-R)$ and NEO Five-Factor Inventory (NEO-FFI) professional manual. Odessa, FL: Psychological Assessment Resources.

Courbalay, A., Deroche, T., Prigent, E., Chalabaev, A., and Amorim, M. A. (2015). Big five personality traits contribute to prosocial responses to others' pain. Personal. Indiv. Diff. 78, 94-99. doi: 10.1016/j.paid.2015.01.038

Daniel, R., De Stavola, B. L., Cousens, S., and Vansteelandt, S. (2015). Causal mediation analysis with multiple mediators. Biometrics 71, 1-14. doi: 10.1111/ biom. 12248

Davis, M. H. (1983). Measuring individual differences in empathy: Evidence for a multidimensional approach. J. Personal. Soc. Psychol. 44, 113-126. doi: 10.1037/ 0022-3514.44.1.113

Decelles, K. A., Derue, D. S., Margolis, J. D., and Ceranic, T. L. (2012). Does power corrupt or enable? When and why power facilitates self-interested behavior. J. Appl. Psychol. 97, 681-689. doi: 10.1037/a0026811

Decety, J., and Yoder, K. J. (2016). Empathy and motivation for justice: Cognitive empathy and concern, but not emotional empathy, predict sensitivity to injustice for others. Soc. Neurosci. 11, 1-14. doi: 10.1080/17470919.2015. 1029593

Deng, S. L., Lin, Y. Q., Liu, Y., Chen, X. Y., and Li, H. X. (2017). How do personality traits shape information-sharing behavior in social media? exploring the mediating effect of generalized trust. Inform. Res. Int. Electr. J. 22:763.

Di Giunta, L., Eisenberg, N., Kupfer, A., Steca, P., Tramontano, C., and Caprara, G. V. (2010). Assessing perceived empathic and social self-efficacy across countries. Eur. J. Psychol. Assess. 26, 77-86.

Dunn, T. J., Baguley, T., and Brunsden, V. (2014). From alpha to omega: A practical solution to the pervasive problem of internal consistency estimation. Br. J. Psychol. 105, 399-412. doi: 10.1111/bjop.12046

Einolf, C. J. (2008). Empathic concern and prosocial behaviors: a test of experimental results using survey data. Soc. Sci. Res. 37, 1267-1279. doi: 10. 1016/j.ssresearch.2007.06.003

Eisenberg, N. (2000). Emotion, regulation, and moral development. Ann. Rev. Psychol. 51, 665-697. doi: 10.1146/annurev.psych.51.1.665

Eisenberg, N., and Miller, P. A. (1987). The relation of empathy to prosocial and related behaviors. Psychol. Bull. 101, 91-119. doi: 10.1037/0033-2909.101.1.91

Eisenberger, N., and Fabes, R. A. (1990). Empathy: Conceptualization. Measur. Relat. Prosoc. Behav. Motivat. Emot. 14, 131-149. doi: 10.1007/BF0099 1640

Erreygers, S., Vandebosch, H., Vranjes, I., Baillien, E., and De Witte, H. (2018). Development of a measure of adolescents' online prosocial behavior. J. Child. Med. 12, 1-17. 
Falanga, R., Caroli, M. E. D., and Sagone, E. (2014). Humor styles, self-efficacy and prosocial tendencies in middle adolescents. Proc. Soc. Behav. Sci. 127, 214-218. doi: 10.1016/j.sbspro.2014.03.243

Fan, J., Meng, H., and Lopez, F. (2006). Validation of an American social self efficacy inventory in Chinese population. Counsel. Psychol. 38(4), 473-496 doi: 10.1037/e518572013-371

Farrelly, D., and Bennett, M. (2018). Empathy leads to increased online charitable behavior when time is the currency. J. Commun. Appl. Soc. Psychol. 28, 42-46. doi: $10.1002 /$ casp. 2339

Ferguson, E., Zhao, K., O'Carroll, R. E., and Smillie, L. D. (2019). Costless and costly prosociality: Correspondence among personality traits, economic preferences, and real-world prosociality. Soc. Psychol. Personal. Sci. 10, 461-471. doi: $10.1177 / 1948550618765071$

Fredrickson, B. L. (2004). The role of positive emotions in positive psychology: The broaden-and-build theory of positive emotions. Am. Psychol. 359, 1367-1377.

Galinsky, A. D., Maddux, W. W., Gilin, D., and White, J. B. (2008). Why it pays to get inside the head of your opponent: The differential effects of perspective taking and empathy in negotiations. Psychol. Sci. 19, 378-384. doi: 10.1111/j. 1467-9280.2008.02096.x

Guo, Q., Sun, P., Cai, M., Zhang, X., and Song, K. (2019). Why are smarter individuals more prosocial? A study on the mediating roles of empathy and moral identity. Intelligence 75, 1-8. doi: 10.1016/j.intell.2019.02.006

Guo, Q., Sun, P., and Li, L. (2018a). Shyness and online prosocial behavior: a study on multiple mediation mechanisms. Comput. Hum. Behav. 86, 1-8. doi: 10.1016/j.chb.2018.04.032

Guo, Q., Sun, P., and Li, L. (2018b). Why neurotic individuals are less prosocial? A multiple mediation analysis regarding related mechanisms. Personal. Indiv. Diff. 128, 55-61. doi: 10.1016/j.paid.2018.02.026

Habashi, M. M., Graziano, W. G., and Hoover, A. E. (2016). Searching for the prosocial personality: A big five approach to linking personality and prosocial behavior. Personal. Soc. Psychol. Bull. 42, 1177-1192. doi: 10.1177/ 0146167216652859

Hampson, S. E. (2012). Personality processes: mechanisms by which personality traits "get outside the skin". Annu. Rev. Psychol. 63, 315-339. doi: 10.1146/ annurev-psych-120710-100419

Hardy, S. A. (2006). Identity, reasoning, and emotion: An empirical comparison of three sources of moral motivation. Motivat. Emot. 30, 205-213. doi: 10.1007/ s11031-006-9034-9

Hardy, S. A., Bean, D. S., and Olsen, J. A. (2015). Moral identity and adolescent prosocial and antisocial behaviors: interactions with moral disengagement and self-regulation. J. Youth Adolesc. 44, 1542-1554. doi: 10.1007/s10964-0140172-1

Hardy, S. A., and Carlo, G. (2011). Moral Identity: What Is It, How Does It Develop, and Is It Linked to Moral Action? Child Devel. Perspect. 5, 212-218. doi: $10.1111 /$ j.1750-8606.2011.00189.x

Hayes, A. F. (2012). Process: A versatile computational tool for observed variable mediation, moderation, and conditional process modeling [white paper]. Available online at: http://www.afhayes.com/public/process2012.pdf

Hayes, A. F., and Coutts, J. J. (2020). Use Omega Rather than Cronbach's Alpha for Estimating Reliability. Commun. Methods Measur. 14, 1-24. doi: 10.1080/ 19312458.2020.1718629

Hertz, S. G., and Krettenauer, T. (2016). Does moral identity effectively predict moral behavior?: a meta-analysis. Rev. Gener. Psychol. 20, 129-140. doi: 10. 1037/gpr0000062

Jennings, P. L., Mitchell, M. S., and Hannah, S. T. (2015). The moral self: A review and integration of the literature. J. Organiz. Behav. 36, S104-S168. doi: 10.1002/job.1919

Karimzade, A., and Besharat, M. A. (2011). An investigation of the relationship between personality dimensions and stress coping styles. Proce. Soc. Behav. Sci. 30, 797-802. doi: 10.1016/j.sbspro.2011.10.155

Karwowski, M., Lebuda, I., Wisniewska, E., and Gralewski, J. (2013). Big Five Personality Traits as the Predictors of Creative Self-Efficacy and Creative Personal Identity: Does Gender Matter? J. Creat. Behav. 47, 215-232. doi: 10.1002/jocb. 32

Khang, H., and Jeong, I. (2016). Perceived self and behavioral traits as antecedents of an online empathic experience and prosocial behavior: Evidence from
South Korea. Comput. Hum. Behav. 64, 888-897. doi: 10.1016/j.chb.2016.08. 010

Kim, Y., and Cohen, T. R. (2015). Moral character and workplace deviance: recent research and current trends. Curr. Opin. Psychol. 6, 134-138. doi: 10.1016/j. copsyc.2015.08.002

Kinnunen, S. P., Lindeman, M., and Verkasalo, M. (2016). Help-giving and moral courage on the Internet. Cyberpsychol. J. Psychosoc. Res. Cybersp. 10:6. doi: 10.5817/CP2016-4-6

Klimecki, O., and Singer, T. (2011). "Empathic distress fatigue rather than compassion fatigue? Integrating findings from empathy research in psychology and social neuroscience," in Pathological Altruism, eds B. Oakley, A. Knafo, G. Madhavan and D.S. Wilson (New York, NY: Oxford University Press), 368-383. doi: 10.1093/acprof:oso/9780199738571.003.0253

Kochanska, G., Forman, D. R., Aksan, N., and Dunbar, S. B. (2005). Pathways to conscience: Early mother-child mutually responsive orientation and children's moral emotion, conduct, and cognition. J. Child Psychol. Psych. 46, 19-34. doi: $10.1111 /$ j.1469-7610.2004.00348.x

Konrath, S. H., O’Brien, E. H., and Hsing, C. (2011). Changes in dispositional empathy in American college students over time: a meta-analysis. Personal. Soc. Psychol. Rev. 15, 180-198. doi: 10.1177/1088868310377395

Kraut, R., Kiesler, S., Boneva, B., Cummings, J., Helgeson, V., and Crawford, A. (2002). Internet paradox revisited. J. Soc. 58, 49-74.

Krettenauer, T., Colasante, T., Buchmann, M., and Malti, T. (2014). The development of moral emotions and decision-making from adolescence to early adulthood: a 6-year longitudinal study. J. Youth Adolesc. 43, 583-596. doi: 10.1007/s10964-013-9994-5

Lai, F. H. Y., Siu, A. M. H., Chan, C. C. H., and Shek, D. T. L. (2012). "Measurement of prosocial reasoning among Chinese adolescents," in Pediatrics, child and adolescent health. Child health and human development yearbook, ed. J. Merrick (New York: Nova Science Publishers), 107-118.

Lee, G., and Lee, W. J. (2010). Altruistic traits and organizational conditions in helping online. Comput. Hum. Behav. 26, 1574-1580. doi: 10.1016/j.chb.2010. 06.003

Lee, S. A. (2009). Does empathy mediate the relationship between neuroticism and depressive symptomatology among college students? Personal. Indiv. Diff. 47, 429-433. doi: 10.1016/j.paid.2009.04.020

Ma, H. K., Li, S. C., and Pow, J. W. (2011). The relation of Internet use to prosocial and antisocial behavior in Chinese adolescents. Cyberpsychol. Behav. Soc. Network. 14, 123-130. doi: 10.1089/cyber.2009.0347

Mak, A. S., and Tran, C. (2001). Big five personality and cultural relocation factors in Vietnamese Australian students' intercultural social self-efficacy. Int. J. Intercult. Relat. 25, 181-201. doi: 10.1016/S0147-1767(00)00050-X

Masten, C. L., Morelli, S. A., and Eisenberger, N. I. (2011). An fMRI investigation of empathy for 'social pain' and subsequent prosocial behavior. NeuroImage 55, 381-388. doi: 10.1016/j.neuroimage.2010.11.060

Melchers, M. C., Li, M., Haas, B. W., Reuter, M., Bischoff, L., and Montag, C. (2016). Similar Personality Patterns Are Associated with Empathy in Four Different Countries. Front. Psychol 7:290. doi: 10.3389/fpsyg.2016.00290

Miller, G. F. (2007). Sexual selection for moral virtues. Q. Rev. Biol. 82, 97-125. doi: $10.1086 / 517857$

Mooradian, T. A., Davis, M., and Matzler, K. (2011). Dispositional empathy and the hierarchical structure of personality. Am. J. Psychol. 124, 99-109. doi: 10.5406/amerjpsyc.124.1.0099

Oda, R., Machii, W., Takagi, S., Kato, Y., Takeda, M., Kiyonari, T., et al. (2014). Personality and altruism in daily life. Personal. Indiv. Diff. 56, 206-209.

Patrick, R. B., Bodine, A. J., Gibbs, J. C., and Basinger, K. S. (2018). What accounts for prosocial behavior? roles of moral identity, moral judgment, and self-efficacy beliefs. J. Gen. Psychol. 179(5), 231-245. doi: 10.1080/00221325.2018.1491472

Podsakoff, P. M., and Organ, D. W. (1986). Self-reports in organizational research: Problems and prospects. J. Manag. 12, 531-544. doi: 10.1177/ 014920638601200408

Preacher, K. J., and Hayes, A. F. (2008). Asymptotic and resampling strategies for assessingand comparing indirect effects in multiple mediator models. Behav. Res. Methods 40, 879-891. doi: 10.3758/BRM.40.3.879

Reich, S. M. (2017). Connecting offline social competence to online peer interactions. Psychol. Popul. Med. Cult. 6, 291-311. doi: 10.1037/ppm00 00111 
Roccas, S., Sagiv, L., Schwartz, S. H., and Knafo, A. (2002). The Big Five Personality Factors and Personal Values. Personal. Soc. Psychol. Bull. 28, 789-801. doi: $10.1177 / 0146167202289008$

Rosen, P. A., and Kluemper, D. H. (2008). The impact of the big five personality traits on the acceptance of social networking website. America: Americas conference on information systems.

Ryan, T., and Xenos, S. (2011). Who uses Facebook? An investigation into the relationship between the Big Five, shyness, narcissism, loneliness, and Facebook usage. Comput. Hum. Behav. 27, 1658-1664. doi: 10.1016/j.chb.2011.02.004

Sherman, R. A., Nave, C. S., and Funder, D. C. (2010). Situational similarity and personality predict behavioral consistency. J. Personal. Soc. Psychol. 99, 330-343. doi: 10.1037/a0019796

Siu, A. M. H., and Shek, D. T. L. (2005). Validation of the Interpersonal Reactivity Index in a Chinese Context. Res. Soc. Work Pract. 15, 118-126. doi: 10.1177/ 1049731504270384

Smillie, L. D., Lawn, E. C., Zhao, K., Perry, R., and Laham, S. M. (2019). Prosociality and morality through the lens of personality psychology. Austr. J. Psychol. 71, 50-58.

Smith, H. M., and Betz, N. E. (2000). Development and validation of a scale of perceived social self-efficacy. J. Career Assess. 8, 283-301. doi: 10.1177/ 106907270000800306

Song, Y., and Shi, M. (2017). Associations between empathy and big five personality traits among Chinese undergraduate medical students. PLoS One 12:e171665. doi: 10.1371 /journal.pone. 0171665

Specht, J., Egloff, B., and Schmukle, S. C. (2011). Stability and change of personality across the life course: the impact of age and major life events on mean-level and rank-order stability of the big five. J. Personal. Soc. Psychol. 101, 862-882. doi: $10.1037 / \mathrm{a} 0024950$

Sproull, L. (2011). Prosocial behavior on the net. Daedalus 140, 140-153. doi: 10.1162/DAED_a_00120

Subrahmanyam, K., Smahel, D., and Greenfield, P. (2006). Connecting developmental constructions to the internet: identity presentation and sexual exploration in online teen chat rooms. Devel. Psychol. 42, 395-406. doi: 10. 1037/0012-1649.42.3.395

Sun, P., Guo, Q., Liu, Z., and Fan, J. (2019). Shyness weakens the agreeablenessprosociality association via social self-efficacy: A moderated-mediation study of Chinese undergraduates. Front. Psychol. 10:1-11. doi: 10.3389/fpsyg.2019. 01084

Taguri, M., Featherstone, J. D., and Cheng, J. (2018). Causal mediation analysis with multiple causally non-ordered mediators. Statist. Methods .Med. Res. 27, 3-19. doi: 10.1177/0962280215615899

Tangney, J. P., Stuewig, J., and Mashek, D. J. (2007). Moral emotions and moral behavior. Annu. Rev. Psychol. 58, 345-372. doi: 10.1146/annurev.psych.56. 091103.070145
Thielmann, I., Spadaro, G., and Balliet, D. (2020). Personality and prosocial behavior: A theoretical framework and meta-analysis. Psychol. Bull. 146, 30-90. doi: $10.1037 /$ bul0000217

Thoms, P., Moore, K. S., and Scott, K. S. (1998). The Relationship between SelfEfficacy for Participating in Self-Managed Work Groups and the Big Five Personality Dimensions. J. Organiz. Behav. 17, 349-362. doi: 10.1002/(SICI) 1099-1379(199607)17:4<349::AID-JOB756>3.0.CO;2-3

Wan, Z. C., and Yang, S. G. (2008). The Revision of Moral self-Identity Scale for Chinese Adolescents. Sci. Soc. Psychol. 23, 457-461.

Williams, K. M., Nathanson, C., and Paulhus, D. L. (2010). Identifying and profiling scholastic cheaters: Their personality, cognitive ability, and motivation. J. Exper. Psychol. Appl. 16, 293-307. doi: 10.1037/a0020773

Winterich, K. P., Aquino, K., Mittal, V., and Swartz, R. (2013). When Moral Identity Symbolization Motivates Prosocial Behavior: The Role of Recognition and Moral Identity Internalization. J. Appl. Psychol. 98, 759-770. doi: 10.1037/ a0033177

Winterich, K. P., Mittal, V., and Ross, W. T.Jr. (2009). Donation Behavior toward In-Groups and Out-Groups: The Role of Gender and Moral Identity. J. Consum. Res. 36, 199-214. doi: 10.1086/596720

Wright, M. F., and Li, Y. (2011). The associations between young adults' face-toface prosocial behaviors and their online prosocial behaviors. Comput. Hum. Behav. 27, 1959-1962. doi: 10.1016/j.chb.2011.04.019

Xie, X., Chen, W., Lei, L., Xing, C., and Zhang, Y. (2016). The relationship between personality types and prosocial behavior and aggression in Chinese adolescents. Personal. Indiv. Diff. 95, 56-61.

Zheng, X. L., Xie, F. W., and Ding, L. (2018). Mediating role of selfconcordance on the relationship between internet altruistic behavior and subjective wellbeing. J. Pac. Rim Psychol. 12, 1-7. doi: 10.1017/prp. 2017.14

Zheng, X. L., Zhu, C. L., and Gu, H. G. (2011). Development of Internet altruistic behavior scale for college students. Chin. J. Clin. Psychol. 19, 606-608.

Conflict of Interest: The authors declare that the research was conducted in the absence of any commercial or financial relationships that could be construed as a potential conflict of interest.

Copyright (c) 2020 Leng, Guo, Ma, Zhang and Sun. This is an open-access article distributed under the terms of the Creative Commons Attribution License (CC BY). The use, distribution or reproduction in other forums is permitted, provided the original author(s) and the copyright owner(s) are credited and that the original publication in this journal is cited, in accordance with accepted academic practice. No use, distribution or reproduction is permitted which does not comply with these terms. 